\title{
Testen Sie Ihr Fachwissen
}

\section{Test Your Knowledge}

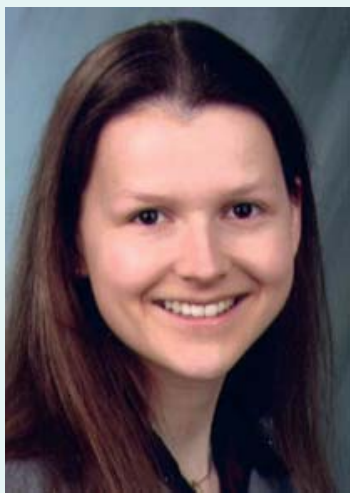

Dr. Carolin-Susanne Morcinietz

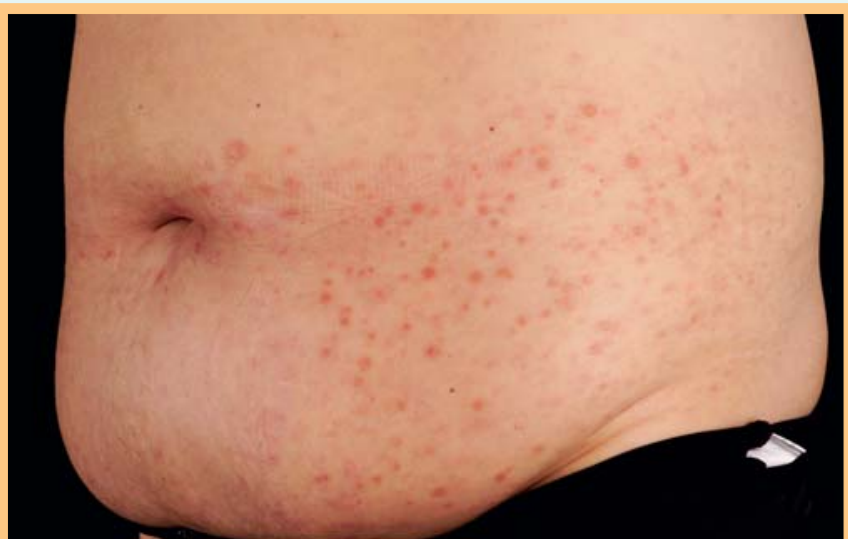

Abb. 1 Klinisches Bild, Übersicht Abdomen.

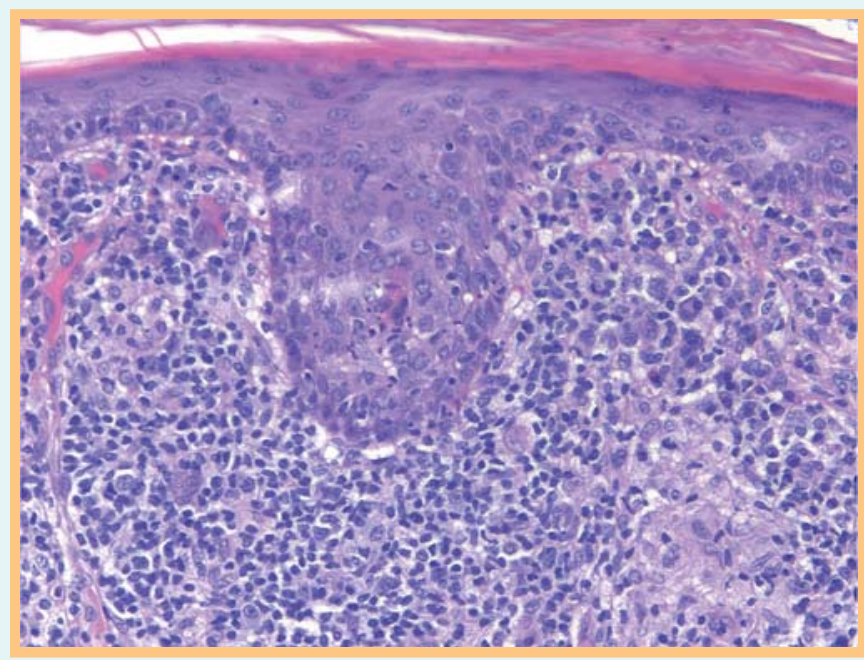

Abb. 2 Histologisches Bild.

\section{Anamnese}

$\nabla$

Bei einer 39-jährigen Patientin traten vor 6 Wochen Halsschmerzen und schmerzhafte Erosionen an der Mundschleimhaut auf. Seit 5 Wochen kam es zur Ausbildung eines makulopapulösen Exanthems am Körperstamm, den Extremitäten und palmar. Seit 3 Wochen bestand zusätzlich eine Fußheberschwäche links. Die Medikamentenanamnese war unauffällig. Dermatologische Vorerkrankungen wurden verneint.

\section{Klinischer Befund \\ $\nabla$}

Bei der Hautinspektion imponierte ein generalisiertes makulopapulöses Exanthem mit Betonung des Körperstammes. Palmar beidseits fanden sich randbetonte, psoriasiform schuppende Erytheme. An der Mundschleimhaut zeigten sich erosive Plaques, der Rachenring war gerötet, die Tonsillen induriert und vergrößert $(\bullet \mathbf{A b b} . \mathbf{1})$.

\section{Histologischer Befund}

$\nabla$

Im Korium zeigt sich ein dichtes, teils lichenoides, zur Tiefe hin perivaskulär akzentuiertes Infiltrat aus Lymphozyten, Histiozyten und insbesondere zur Tiefe hin auch reichlich Plasmazellen ( Abb. 2).

\section{Klinische Differenzialdiagnose \\ $\nabla$ \\ Arzneimittelexanthem \\ Lichen ruber \\ Parapsoriasis lichenoides \\ Pityriasis rosea \\ Syphilis Stadium II}

Was ist die korrekte Diagnose?

\section{(Auflösung nächste Seite)}




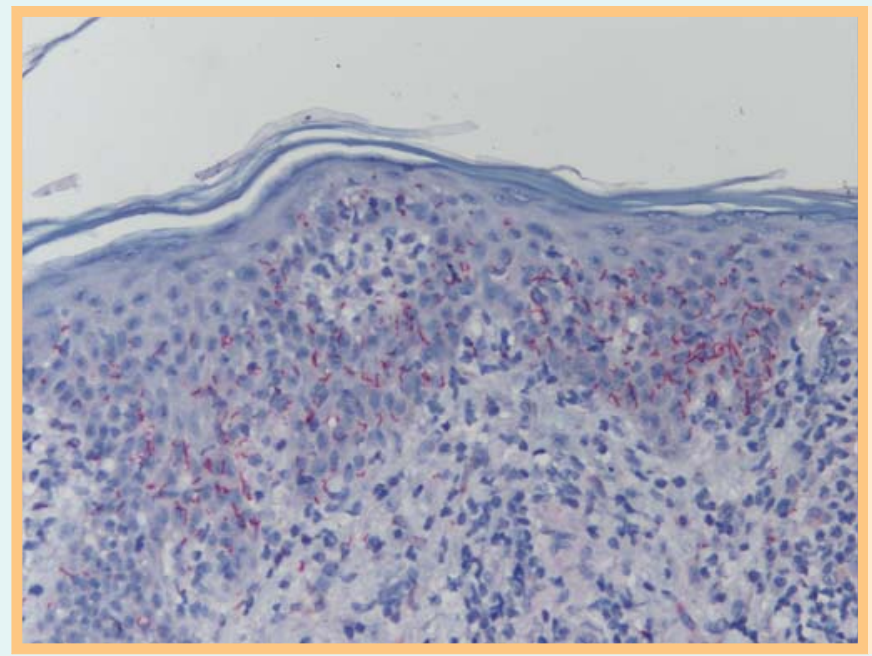

Abb. 3 Immunhistochemie.

\section{Auflösung}

$\nabla$

Abschließende Diagnose:

Syphilis Stadium II

Makulopapulöses Syphilid ( Abb. 3)

Serologischer Untersuchungsbefund:

- Treponema pallidum Antikörper TPPA $1: 204800 \quad($ Norm $<1: 80)$

- Treponema pallidum IgG-Antikörper Immunoblot

8 Index (positiv) $\quad($ Norm $<3)$

- Treponema pallidum IgM-Antikörper Immunoblot 6 Index (positiv) $\quad($ Norm $<2)$

- Treponema pallidum RPR (Reagin) $1: 160$

$($ Norm $<1: 1)$

Liquordiagnostik:

ohne pathologischen Befund

Kommentar: Das klinische Bild einer Syphilis im Stadium II kann sehr vielgestaltig sein und reicht von disseminierten makulopapulösen, psoriasiformen Läsionen an Körperstamm und Extremitäten über Schleimhautbefall mit Erosionen bis hin zu Condylomata lata. Zusätzlich klagen die Patienten über unspezifische Allgemeinsymptome wie Müdigkeit, allgemeines Krankheitsgefühl, Fieber, Halsschmerzen, generalisierte Lymphadenopathie sowie Kopf- und Muskelschmerzen. In unserem Fall berichtete die Patientin zusätzlich über eine neu aufgetretene Fußheberschwäche links.

In der histologischen Aufarbeitung der Probeexzision vom Abdomen imponierte ein dichtes lichenoides Infiltrat mit zahlreichen Plasmazellen. Bei einer solchen Konstellation sollte immer auch das Vorliegen einer Syphilis durch weitere Untersuchungsmethoden ausgeschlossen werden.

Neben dem direkten Erregernachweis aus Reizserum in der Dunkelfeldmikroskopie und dem serologischen Nachweis spezifischer Antikörper kann die Diagnose auch durch den Nachweis des Erregers im Gewebe gesichert werden (Immunhistochemie, PCR [1]). Gerade bei unklaren Fällen kann daher die Histologie einen wichtigen Beitrag zur Diagnose leisten [2,3]. Im vorliegenden Fall konnte die Diagnose durch alle diese Methoden gesichert werden. Aufgrund der neurologischen Symptomatik erfolgte vor Therapieeinleitung eine Liquorpunktion mit unauffälligem Resultat.

Die Therapie erfolgte mit Benzylpenicillin-Benzathin $2 \times 1,2$ Mio. I.E. i.m. unter prophylaktischer Gabe von Prednisolon $1 \mathrm{mg} / \mathrm{kg}$ Körpergewicht p. o. zur Vermeidung einer Jarisch-Herxheimer-Reaktion.

Der Hautbefund ist unter der antibiotischen Therapie abgeheilt. In der serologischen Kontrolle 3 Monate nach Therapie zeigten sich deutlich rückläufige Titerwerte (TPPA 1 :640, IgM-AK Immunoblot 4, IgG-AK Immunoblot 12). Die neurologischen Symptome bezüglich der Fußheberschwäche waren unverändert. Es erfolgte eine weitere neurologische Diagnostik, in der eine Peronaeusparese links aufgrund eines Bandscheibenvorfalles mit Teilmaskierung der Nervenwurzel L5 links festgestellt und mittels Krankengymnastik und physikalischer Therapie behandelt wurde.

\section{Literatur}

1 Behrhof W, Springer E, Bräuninger W et al. PCR-testing for Treponema pallidum in paraffin-embedded skin biopsies: test design and impact on the diagnosis of syphilis. J Clin Pathol 2008; 61 (3): 390-395

2 Anemüller $W$, Bräuninger W, Krahl D et al. Primäraffekt am Finger unter dem Bild einer chronischen Paronychie - Umwege zur Diagnose. Hautarzt 2008; 59 (6): $499-502$

3 AWMF-Leitlinie 059/002 Diagnostik und Therapie der Syphilis der Deutschen STD-Gesellschaft (DSTDG) von 2008 